\title{
ARD
}

Annals of the Rheumatic Diseases

Leader

\section{Quality of life-a measure too far?}

In 1989 the United Kingdom NHS Review Working Paper on Medical Audit defined audit as: '...the systematic, critical analysis of the quality of medical care, including the procedures used for diagnosis and treatment, the use of resources, and the resulting outcome and quality of life for the patient. ${ }^{1}$

This gave impetus to the need to measure quality of life after health care intervention. Since then a minor industry has developed in reviewing the available measures and discussing the 'best buys' with regard to validity, reliability, and responsiveness to change. ${ }^{2-4}$ As the momentum of using quality of life as an outcome measure in health care increases, occasional voices are raised which question the lack of a conceptual basis for much of the current work. ${ }^{5-7}$ If these concerns are valid, we must consider their implication. Thus it is worth taking some time to reflect on 'quality of life' and to ask three key questions. What is it? Where does it fit in with the measures of outcome used routinely in rheumatology? In the light of the answers to these, is it a worthwhile outcome measure for rheumatologists to pursue?

Quality of life (and for all practical purposes this can be equated to the term 'subjective well being ${ }^{8}{ }^{9}$ ) is seen as a multidimensional construct comprising three elements: cognitive judgment, positive affect, and negative affect. ${ }^{1011}$ Measures of 'life satisfaction' have been used to reflect the cognitive judgment component of quality of life; ${ }^{12}$ other measures have been developed specifically for positivenegative emotions. ${ }^{13} 14$ Some 20 years of theoretical and empirical work underpin this now commonly accepted understanding of quality of life. The crucial aspect of quality of life for rheumatology, and health care in general, is that health, or for example wealth, is seen not as an inherent or even necessary component of quality of life, but rather as a potential influence. ${ }^{8}$

Other factors are known to mediate quality of life for the individual. These may be divided into two domains: personal-psychological and demographic-cultural. For example, factors such as self esteem, locus of control, religious belief, and coping skills have been shown to influence quality of life. ${ }^{15-18}$ Similarly, age, gender, marital status, employment status, and ethnicity have also been shown to influence quality of life. ${ }^{19-23}$

How does this understanding of quality of life fit in with the current measures of outcome in rheumatology? We can conceptualise outcome within the disease-impairmentdisability-handicap (IDH) model proposed by the World Health Organisation. ${ }^{24}$ At the simplest level, disease gives rise to impairment which, in turn, can give rise to disability. Thus impairments such as pain, limited range of motion, or fatigue, can give rise to disabilities, for example in walking, dexterity, or personal care. There are many measures which focus on impairment and disability, but the Health Assessment Questionnaire (HAQ) ${ }^{25}$ and Arthritis Impact Measurement Scales (AIMS) ${ }^{26}$ are two of the better known measures used in rheumatology. Impairments and disabilities are mediated by environmental and societal factors to produce handicap, for example, in physical independence or mobility. To date, few measures have been developed for handicap, although some components of existing instruments, for example those that measure social integration, may demonstrate various degrees of association with the handicap scale. Measures which describe the characteristics of the disease-IDH continuum are best described as 'health status' measures, as this is precisely what they measure ${ }^{6}$ (the absence, or presence of disease and its consequences).

With an understanding of quality of life, together with the consequences of disease as implied in the IDH concept, it is possible to put together a model which shows the relationship between health status and quality of life. The figure shows that health status is but one possible influence on quality of life. Just as personal and cultural variables can mediate between disability and handicap, so they also mediate between health status and quality of life.

Unfortunately, most recent quality of life reviews express the concept in terms of impairment and disability. Such a view is typified by the 'health related quality of life' approach, ${ }^{27}{ }^{28}$ and is based on the claim that as health care cannot influence the many mediating influences of quality of life, it need not take the trouble to measure them. Thus it redefines quality of life as mostly impairment and disability, with some handicap (for example social integration). Such an approach represents the single largest impediment to a scientific approach to measuring quality

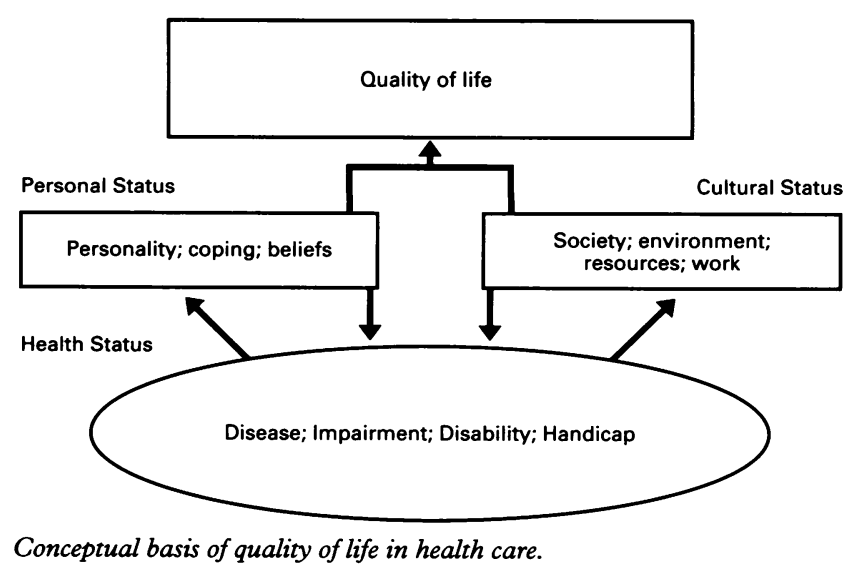


of life in rheumatology. Lacking any theoretical basis and thus, by definition, devoid of construct validity for quality of life, it performs a feat of methodological alchemy. It transmutes existing impairment and disability measures, validated for quite a different purpose, into so-called quality of life. As health status typically accounts for only a small part of the variation in quality of life, ${ }^{9}$ one can only despair at the psychometric properties of measurement associated with such an approach.

Rheumatologists should not be ashamed of the fact that much of their intervention is concerned with reducing pain and fatigue (impairments), in improving - or at least maintaining - function (disability), and in maintaining or improving independence and mobility (handicap). There is no need to dress up these worthy outcomes as something different!

We must therefore ask, is there any need to go further and measure quality of life-is it a measure too far? If the component of health status contributes only a proportion of the variation in quality of life, it is likely that the sensitivity to change for quality of life measures will be too low for most practical purposes. Yet, at the same time, the rheumatologist or therapist knows that intervention can improve quality of life, as patients spontaneously report such an improvement!

The problem lies in the subjective nature of quality of life, making it a personal matter with its attendant mediating factors. However, as there is already a clear theoretical framework for quality of life, in addition to various available measures, ${ }^{3}$ hypotheses may be drawn up and tested concerning the relationships between health status and quality of life, as suggested by the figure. Although the mediating factors must be taken into account, most of the cultural factors are already measured in rheumatological research.

An alternative approach to this more complex 'model' is the measurement of quality of life indirectly, through the 'needs based' approach. ${ }^{29}$ Here the impact of the diseaseIDH continuum on peoples lives is explored in depth. Content analysis of this exploration then gives rise to a set of items which reflect unmet need associated with a particular disease. These items can then be developed into a scale using standard psychometric methods. The advantage of this approach is twofold: first it accords with the understanding that part of the influence of health on quality of life is not simply the direct effect on how people feel physically, but also the effect on what their health allows them to $\mathrm{do}^{8}$ second, the items derived reflect the subjective expression of the impact of the disease on people's lives, taking into account many mediating factors, for example, coping strategies. One would thus expect these scales to have a much closer association with quality of life, but at the same time be more sensitive to changes brought about by therapeutic intervention. Empirical validation of these attributes is yet to be confirmed, but the approach is attractive because of its theoretical base and simplicity of measurement.

It is clear that a theoretically based approach to quality of life measurement in rheumatology will need a willingness to accept the limitations of health care intervention for improving quality of life. Nevertheless, existing and new approaches to quality of life, based on theory and subjective views of those experiencing disease, do offer an opportunity to explore quality of life as a valuable component of outcome. If rheumatologists are prepared to accept that much of their work is concerned with the disease-IDH continuum, this foundation makes them well placed to take a leading role in a sound approach to quality of life research in health care.

School of Medicine,

Rheumatology and Rehabilitation Research Unit,

ALAN TENNANT

University of Leeds, Leeds LS2 9NZ,

United Kingdom

1 National Health Service Review. Working Paper No 6 Medical Audit. London: HMSO, 1989.

2 Fallowfield L. The quality of life. London: Souvenir Press, 1990.

3 Bowling A. Measuring health. A review of quality of life measurement scales. Buckingham: OUP, 1991

4 Fitzpatrick $R$. The measurement of health status and quality of life in rheumatological disorders. Baillière's Clin Rheumatol 1993; 7: 297-317.

5 Mor V, Guadagnoli E. Quality of life measurement: A psychometric Tower of Babel. $¥$ Clin Epidemiol 1988; 41: 1055-8.

6 Bergner $M$. Health status as a measure of health promotion and disease prevention: unresolved issues and the agenda for the 1990's. In Proceedings of the 1989 Public Health Conference on Records and Statistics. Rockville, MD: National Centre for Health Statistics, 1989.

7 Van Riel P L C M, Van Lankveld W G J M. Quality of life 3. Pharmacy World and Science 1993; 15: 93-7.

8 Diener E. Subjective well-being. Psychol Bull 1984; 95: 542-75.

9 Fuhrer M J. Subjective well-being: Implications for medical rehabilitation outcomes and models of disablement. Am $\mathcal{F}$ Phys Med Rehabil 1994; 73: 358-64.

10 Bradburn N M. The structure of psychological well-being. Chicago: Aldine, 1969.

11 Andrews F M, Withey S B. Social indicators of well-being: America's perception of life quality. New York: Plenum Press, 1976

12 Wood V, Wylie M L, Scheafor B. An analysis of a short self-report measure of life satisfaction: correlation with rater judgements. $\mathcal{F}$ Gerontol 1969; 24

13 Kammann R, Flett R. Affectometer 2: A scale to measure current level of general happiness. Aust f Psychol 1983; 35: 257-65.

14 Andrews F M, McKennel A C. Measures of self-reported well-being: their affective, cognitive and other components. Social Indicators Res 1980; 18 127-55.

15 Schwartz A N. An observation of self-esteem as the linchpin of quality of life for the aged. An essay. Gerontologist 1975; 15: 470-2.

16 Chang B L. Locus of control, trust, situational control and morale of the elderly. $₹$ Nurs Studies 1979; 16: 169-81.

17 Hadaway C K. Life satisfaction and religion: A re-analysis. Social Forces 1978; 57: $636-43$.

18 Billings A G, Moos R H. The role of coping responses and social resources in attenuating the impact of stressful life events. $\mathcal{F}$ Behav Med 1981; 4 139-57.

19 Medley M L. Life satisfaction across four stages of adult life. Int 7 Aging Hum Dev 1980; 11: 193-209.

20 Cameron P. Mood as an indicator of happiness. Age, sex, social class and situational differences. F Gerontol 1975; 30: 216-24.

21 Glenn N D. The contribution of marriage to the psychological well-being of males and females. $\mathcal{F}$ Marriage Family 1975; 37: 594-600.

22 Campbell A. Subjective measures of well-being. Am Psychol 1976; 31: 117-24.

23 Clemente F, Sauer W J. Racial differences in life satisfaction. $\mathcal{f}$ Black Studies 1976; 7: 3-10.

24 World Health Organisation. The international classification of impairments, disabilities and handicaps. Geneva: WHO, 1980

25 Fries J F, Spitz P W, Kraines R G, Holman H R. Measurement of patien outcome in arthritis. Arthritis Rheum 1980; 23: 137-45.

26 Meenan R F, Gertman P M, Mason J H. Measuring health status in arthritis: the Arthritis Impact Measurement Scales. Arthritis Rheum 1980; 23: 146-52.

27 Kaplan R M, Bush J W. Health related quality of life measurement for evaluation research and policy analysis. Health Psychol 1982; 1: 61-80.

28 Kaplan R M, Coons S J, Anderson J P. Quality of life and policy analysis in arthritis. Arthritis Care Res 1992; 5: 173-83.

29 Hunt S M, McKenna S P. The QLDS: A scale for the measurement of quality of life in depression. Health Policy 1992; 22: 307-19. 